\section{Epitheliogenesis imperfecta in a crossbred Holstein calf, southwestern Iran}

\author{
Shahrzad Azizi,1 \\ Mehdi Amirmohammadi,2 \\ Reza Kheirandish, ${ }^{1}$ Paria Dahesh ${ }^{3}$ \\ 1Department of Pathobiology, Faculty of \\ Veterinary Medicine, Shahid Bahonar \\ University of Kerman; 2Jiroft Branch, \\ Islamic Azad University, Young \\ Researchers Club, Jiroft; ${ }^{3}$ Graduated of \\ Veterinary Medicine Faculty, Shahid \\ Bahonar University of Kerman, Iran
}

\begin{abstract}
Epitheliogenesis imperfect (EI) is a rare autosomal recessive skin defect that is clinically identified with absence of cutaneous epithelium of the limbs, muzzle and nostrils as well as oral mucous membranes. This congenital newborn desease is reported mainly in domestic animals. The present study described EI in a 13 day-old, female crossbred Holstein calf. Gross examination showed epithelium agenesis of two front and hind limbs skin around the carpal and tarsal joints, and also extensive areas of the metacarpal and metatarsal regions. The calf died 5 days after antibiotic therapy and use of topical cream.
\end{abstract}

\section{Introduction}

Epitheliogenesis imperfecta (EI) is a rare autosomal recessive disorder of skin. This congenital defect is clinically characterized by absence of the skin epithelium, specially distal part of the limbs, muzzle, nostrils, as well as oral mucous membranes. ${ }^{1} \mathrm{EI}$ is a newborn desease and reported mainly in domestic animals such as calfs, ${ }^{2}$ sheep,${ }^{3}$ equines, ${ }^{4}$ kittens, ${ }^{5}$ swines, ${ }^{6}$ beagle pups, ${ }^{7}$ and also in wild species. ${ }^{8} \mathrm{EI}$ is known essentially in in bovine breeds. The first report in cattle was described by Hadley. ${ }^{1}$ Other defects such as brachygnathia, atresia ani, dental and ocular abnormalities may be seen with EI.9,10 Due to available of organisms to under epithelium tissues, affected animals die a short time after birth because of septicemia or secondary to dehydration and electrolyte abnormalities resulting from loss of water from the nonepithelialized surfaces. ${ }^{1,10}$ Neonates with minimal lesions may survive by supportive treatment until the defects become filled by scar tissues. 10 The present study described EI in a newborn calf.

\section{Case Report}

A 13 day-old female crossbred Holstein calf in the Jiroft district, Kerman province, Iran, was referred for treatment of erosive and ulcerative skin lesions. Clinical examinations showed tachycardia, arrhythmia, high respiration rate and body temperature about $39.5^{\circ} \mathrm{C}$.

Gross inspection showed epithelium of the skin covered on both front and hind limbs around the carpal and tarsal joints, and also extensive areas of the metacarpal and metatarsal regions were not formed. In addition, there was no epidermis over the muzzle, nostrils and lips. The lesions were apparently bright red, glistening, depressed and extended both medially and laterally. They were covered with reddish to brownish crusts. The lesions were well-emarcated in variable size and shape (Figure 1). Mucous membrane of oral cavity was intact. Antibiotic therapy was done with oxytetracyline spray and penicillin. Also, silver creams was applied topically but the calf survived for five days after treatment.

\section{Discussion and Conclusions}

Congenital agenesis of cutaneous epithelium occurs, as two different diseases, including epidermolysis bullosa and aplasia cutis, have similar clinical lesions. ${ }^{11-13}$

EI, also known as aplasia cutis, has various types: the classic form (type 1) is lethal and diagnosed by lack of epithelial skin mainly limb extremities, deformed ears due to auricular epithelial defects, muzzle, and oral cavity. 14 EI has been documented in different breeds of calves including Holstein, Jersey, Shorthorn, Dutch Black Pied, Swedish Red Pied, German Yellow Pied, Hereford, Ayrshire, Angus, Jersey, Brown Swiss and Sahiwal.2,15,16 No sex predilection is known and both male and female calves are affected.10 There is a hypothesis that EI may be caused by disturbance in metabolism of fibroblast that results in damage to the epithelium nurishment. A study by Fery and colleagues ${ }^{14}$ on skin of calf affected by EI showed fissures and blisters between the basal cells and the reduction of collagen and lipid synthesis by fibroblasts.

In the present case, EI was observed in a female crossbred Holstein calf. In the present study, congenital skin lesions in the calf were not severe and concentrated only over two front and hind limbs, muzzle and nostrils. Oral and hoof lesions were not found. No other abnormalities were associated with EI. Treatment with antibiotics and topical cream was not effective. The calf survived only 5 days after supportive treatments. EI was described in a number of animal species with similar
Correspondence: Shahrzad Azizi, Department of Pathobiology, Faculty of Veterinary Medicine, Shahid Bahonar University of Kerman, Kerman, Iran

E-mail: azizi.shahrzad@gmail.com

Key words: Epitheliogenesis imperfecta, calf, pathology

Conflict of interest: the authors declare no potential conflict of interest.

Received for publication: 6 October 2015.

Accepted for publication: 21 October 2015.

This work is licensed under a Creative Commons Attribution NonCommercial 4.0 License (CC BYNC 4.0).

(C) Copyright S. Azizi et al., 2016

Licensee PAGEPress srl, Italy

Veterinary Science Development 2016; 6:6238

doi:10.4081/vsd.2016.6238

clinical lesions but different severity. In the previous studies on EI in cattle, lesions have been found in skin of digital extremities, flanks, muzzle, oral mucosa, tongue, hard palate, cheeks, and esophagus.1,16 Hutt and colleagues 17 reported similar results in Ayrshire calves. Also, they described that epithelial defects in Jersey calves may be accompanied by brachygnathia inferior and atresia ani.

The prognosis of EI depends on the size of lesions. Septicemia and death occur in severe cases. Mild lesions may be repaired by scar formation or surgery method. ${ }^{1}$ Venkataramanan and colleagues ${ }^{18}$ reported epitheliogenisis imperfecta in a graded Friesian calf. The calf survived after treatment with injections of sulfadiazine, trimethoprim, pheneramine mallet and zinc oxide cream. Complete resolution was noticed within 3 months and the calf survived.

EI in other animal species occurs with similar lesions. Lieto and colleagues ${ }^{4}$ described EI in two American saddlebred foals. They observed defects in epithelium of the skin and oral mucosa as well as dental abnormalities. Separation of the epidermis from dermis and division within the lamina lucida of the basal lamina were observed in the light and transmission electron microscopy, respectively. The intact skin of the EI-affected foals showed abnormality in hemidesmosomes junctions. The morphological and ultrastructural findings in the affected foals were similar to Herlitz junctional epidermolysis bullosa in human, which is caused by a defect in one of the subunits of laminin-5. The close similarity of lesions of the human and equine diseases suggests that EI may be caused by a laminin-5 defect. Azimpour and colleagues ${ }^{3}$ reported EI in a lamb. The hair coat was absent on the car- 


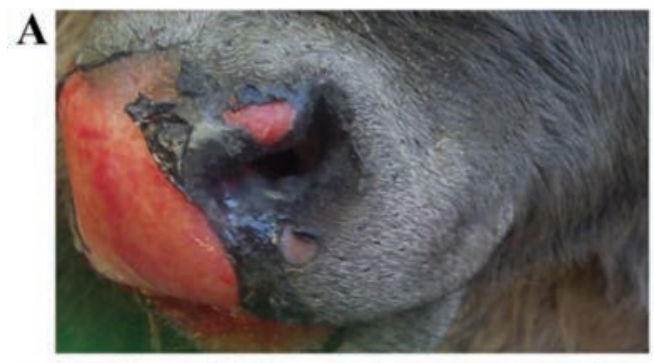

B

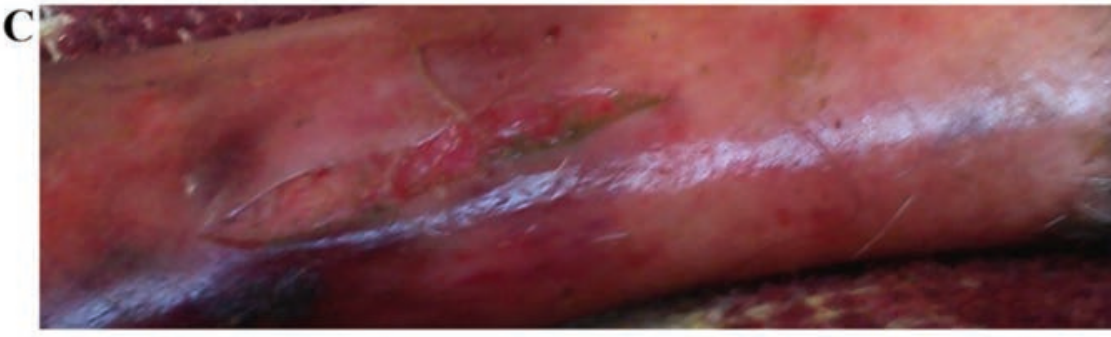

Figure 1. Epitheliogenesis imperfecta in a calf. Extensive well demarcated bright red to brownish areas of epithelial agenesis on the muzzle, nostrils, lips (A) and limb (B and C).

pus and tarsus of the limbs and thinned around the eyes. Also, lesions with crust were found in the oral cavity on the gum, hard plate, and tongue. ${ }^{3}$

This condition is common in herds with extensive inbreeding. ${ }^{10}$ Selective breeding stock can be used for prevention of EI. ${ }^{2}$

\section{References}

1. Hadley FB. Congenital epithelial defects of calves. J Hered 1927;18:487-95.

2. Raverty S, Mcintosh D, Coates J. Epitheliogenesis imperfecta in Simmental and Aberdeen Angus, Hereford-cross neonates. Animal Health Center Newslett. Ministry of Agriculture, Food and
Fisheries, British Columbia. 2000;10:3.

3. Azimpour S, Gholamhoseini B, Shaghayegh A. First report of congenital epitheliogenesis imperfecta in a lamb from Iran. Comp Clin Path 2015;24:247-50.

4. Lieto LD, Cothran EG. The epitheliogenesis imperfecta locus maps to equine chromosome 8 in American Saddlebred horses. Cytogene Genome Res 2003;102:207-10.

5. Munday BL. Epitheliogenesis imperfecta in limbs and kittens. Br Vet J 1970;126:47.

6. Benoit-Biancamano M0, Drolet R, D'Allaire S. Aplasia cutis congenita (Epitheliogenesis imperfecta) in swine: observations from a large breeding herd. J Vet Diagn Invest 2006;18:573-9.

7. Gupta BN. Epitheliogenesis imperfecta in a dog. Am J Vet Res 1973;34:443-4.

8. Baker JR, Lyon DG. Epitheliogenesis imperfecta and gonadal malformation in pumas (Felis concolor). Vet Rec 1983;112:37.

9. Scott DW. Congenital and hereditary diseases. In: Large Animal Dermatology. 1988. p 339.

10. Jubb KVF, Kennedy CP. Pathology of domestic animal, 4th ed. New York, USA: Academic Press; 2007.

11. Scott DW, Miller WHJ. Congenital and hereditary skin diseases. In: Scott DW, Miller WH eds. Equine dermatology. St. Louis, MO: WB Saunders Company; 2003. pp 628-46.

12. Cameron RDA. Diseases of the skin. In: Straw BE, Zimmerman JJ, D'Allaire S, Taylor DJ, eds. Diseases of swine, $9^{\text {th }}$ ed. Ames, IA: Blackwell Publishing; 2006. p 195.

13. Radostits OM, Gay CC, Hinchcliff KW, Constable PD. Veterinary medicine. Philadelphia, USA: Saunders Elsevier; 2007. pp 1975.

14. Frey J, Chamson A, Gourreau JM, Gillet JP. Collagen and lipid biosynthesis in a case of epitheliogenesis imperfecta in cattle. $\mathrm{J}$ Invest Dermatol 1989;93:83-6.

15. Jayasekara MU, Leipold HW. Epitheliogenesis imperfecta in Shorthorn and Angus cattle. Zentralbl Veterinarmed A 1979;26:497-501.

16. Dalir-Naghadeh B, Seifi HA, Farshid AA. Congenital bovine epitheliogenesis imperfecta: a report of three cases from Iran. J Vet Med A Physiol Pathol Clin Med 2004;51:409-12.

17. Hutt FB, Frost JN. Hereditary epithelial defects in Ayrshire cattle. J Hered 1948;39:131-7.

18. Venkataramanan R, Srinivasan P, Murali N, Balakrishnan S. Epitheliogenesis imperfecta in a Graded Friesian calf. Tamilnadu J Vet Anim Sci 2010;6:60-4. 